\title{
Sobre a importância da transversalidade de gênero para o debate feminista contemporâneo
}

\author{
Veronica Calado
}

\begin{abstract}
Resumo: O primeiro tratado versando sobre a necessidade do desenvolvimento de cooperação internacional para a defesa dos direitos humanos, independentemente de raça, sexo, língua ou religião, foi a Carta das Nações Unidas (1945). A partir de então outros documentos, tais como a Convenção Interamericana sobre a concessão dos direitos civis à mulher (1948), Convenção sobre os Direitos Políticos (1953), Convenção para eliminar todas as formas de discriminação contra a mulher (1979), foram firmados. No Brasil, a questão da desigualdade de gênero voltou a ser debatida, na esteira no processo de redemocratização nacional, a partir da década de 1980. Não obstante, a agenda política internacional persiste na defesa da superação da desigualdade sob o viés individual, ignorando sua interface com outras questões, tais como: pobreza, raça ou etnia, entre outras. Negligenciam-se também aspectos importantes ao debate, tais como a desnaturalização e a dimensão identitária do corpo, e a ética feminista da negação do dever de cuidado. Observar a mulher para além dos limites impostos pela divisão sexual e social do trabalho pode auxiliar no processo de efetivação dos direitos e garantias fundamentais assegurados a esse grupo focal pela via normativa, mas reiteradamente negados pelos costumes.
\end{abstract}

Palavras-chave: Gênero - Transversalidade - Políticas públicas - Direito das mulheres Feminismos

\section{On the importance of gender transversality for the contemporary feminist debate}

\begin{abstract}
The first treaty about the necessity of developing international cooperation to the defense of the human rights, independently of race, gender, language or religion, was the Charter of the United Nations, in 1945. In time, other documents, like the Inter-American Convention on Granting of Civil Rights to Woman (1948), Convention on the Political Rights of Woman (1953), Convention on the Elimination of All Forms of Discrimination against Women (1979) have been ratified. In Brazil, the gender inequality started to be debated with the redemocratization process in the 1980s. However, the international politics agenda persists on defending overcoming inequality under the individual bias, ignoring its interface with other issues, such as: poverty and race, for example. Other important aspects of the debate, such as the denaturalisations and the identity dimension of the body and the feminists ethics of the denial of the duty of care, are also ignored. Observing women beyond the limits imposed by sexual and social division of work can be an alternative to the process of enforcement of human rights assured to this group by law, but repeatedly denied by culture.
\end{abstract}

Keywords: Gender - Transversality - Public polities - Woman's right - Feminisms

\footnotetext{
${ }^{1}$ Mestranda em Filosofia pela Universidade Federal do Paraná, Curitiba, Brasil; Mestra em Direito Empresarial e Cidadania pelo Centro Universitário Curitiba. E-mail: veronica.calado@ufpr.br
} 
“Os homens brancos que escreveram aquelas palavras não entendiam que todos os homens não significavam verdadeiramente todos os homens. Não se eles tomavam o que pertencia a outras pessoas, independentemente de ser algo que se podia segurar na mão, como a terra, ou não, como a liberdade"

The Underground Rairoad, Colson Whithead

\section{Introdução}

O século XX foi marcado pela intensificação do debate acerca da isonomia entre os indivíduos, uma vez que a dignidade da pessoa humana foi deslocada para o centro do debate político mundial. Versando sobre a necessidade do estreitamento de vínculos de cooperação internacional para a defesa dos direitos humanos, independentemente de critérios como etnia, sexo ou credo religioso, o primeiro tratado celebrado nesse sentido foi a Carta das Nações Unidas, de 1945. Na sequência, com o intuito de reforçar a concessão de proteção aos grupos focais em situação de maior vulnerabilidade social, outras tantas normas internacionais também foram firmadas na esteira da Carta de 1945.

Evidenciando-se a necessidade de concessão de especial proteção às mulheres, a partir do ano de 1948, normas jurídicas especificamente voltadas ao reconhecimento e ampliação de seus direitos civis e políticos passaram a ser produzidas em âmbito internacional e, posteriormente, ratificadas por diversos países.

À proteção internacional das mulheres somaram-se os seguintes documentos: Convenção Interamericana sobre a concessão de direitos civis às mulheres (1948), Convenção sobre os direitos políticos (1953), Convenção para eliminar todas as formas de discriminação contra a mulher (1979), entre outros. Seguindo a tendência internacional, o Brasil, sobretudo a partir do processo de redemocratização iniciado na década de 1980 , passou a se ocupar de questões relacionadas à desigualdade entre homens e mulheres, razão pela qual o tema voltou a ser debatido, tendo sido observado, como consequência disso, considerável aumento no que diz respeito à produção legislativa nessa área.

Não obstante os inegáveis avanços nessa área, não há dúvidas de que a questão da violência contra as mulheres, em todas as suas formas de manifestação (quais sejam: física, psíquica ou institucional), ainda persiste, tanto no plano internacional, quanto em âmbito interno. Dados demonstram que no ano de 2015 registrou-se aumento de 12,5\% na taxa de homicídios contra mulheres, razão pela qual o Brasil passou a ocupar a $5^{\text {a }}$ colocação no ranking de países em que mais se mata mulheres. ${ }^{2}$ Soma-se a esta controvérsia o considerável aumento de casos de denúncia de violência contra mulheres lésbicas, bissexuais e transexuais, tendo sido registrado, entre os anos de 2014 e 2015, aumento de 821 denúncias ${ }^{3}$ por intermédio do Disque Direitos Humanos ou Disque 100 - serviço de proteção a vítimas de violência, que tem se consolidado como principal centro de recebimento de denúncias de casos de violação de direitos humanos contra população LGBT.

A dificuldade de promoção de debate político sobre questões de gênero apenas evidencia a urgência do tema; torna-se cada vez mais necessária a busca pela realização da

${ }^{2}$ Cf. WAISELFISZ, Mapa da violência 2015: Homicídio de mulheres no Brasil.

${ }^{3}$ BRASIL, Violência LGBTFóbicas no Brasil. 
igualdade substancial entre os indivíduos, sob pena de que sejam reforçados tanto o quadro de violência, como o de discriminação, contra todos os grupos que se encontram acobertados apenas teoricamente pelo discurso da centralidade da dignidade humana, enquanto são sistematicamente desamparados pelos costumes.

Vale ressaltar, em que pese a importância da declaração solene da dignidade humana no discurso político contemporâneo, que não se pode ignorar que sua centralidade formal não tem sido suficientemente capaz de consolidar a igualdade material entre os indivíduos, sendo inegável que diferentes formas de socialização de indivíduos, ainda hoje, tornam alguns grupos mais vulneráveis à marginalização social que outros. Assim sendo, parece acertada a conclusão de que a busca pela extensão da igualdade, como um dos principais efeitos da Revolução Francesa, parece ter encontrado um limite, a saber: a função meramente enunciativa do Direito. À superação das desigualdades, portanto, é imprescindível a adoção de medidas voltadas para a correção das assimetrias sociais.

Posto isto, partindo de pesquisa em aporte bibliográfico e dados estatísticos sobre o tema, o presente ensaio tem por objetivo investigar a seguinte questão: em que medida a adoção de políticas públicas transversais às questões de gênero pode contribuir para a superação do quadro de naturalização da violência contra mulheres?

\section{Feminismos: entre avanços e retrocessos}

À medida que o movimento feminista, espécie de "filho indesejado" da Revolução Francesa ${ }^{4}$, avançou em suas críticas, tornou-se perceptível a existência de sucessivos processos culturais e políticos, retroalimentados, que fortaleciam o argumento da submissão feminina e, como decorrência disso, a naturalização da violência contra mulheres. $\mathrm{Na}$ literatura ocidental, sobretudo na passagem dos séculos XVIII ao XIX, tornaram-se abundantes os exemplos de narrativas desenvolvidas tomando por empréstimo a temática de relações sociais pautadas em modelos patriarcais e desiguais, em que ora a submissão era ovacionada, ora duramente criticada.

Tomando por empréstimo a obra Madame Bovary, de Gustave Flaubert (1881-1880), podemos observar a comovente alegria da sra. Héloïse Bovary quando descobre que a futura esposa de seu filho Charles, a então srta. Emma Rouault, recebera primorosa educação no convento em que havia crescido, tendo adquirido as habilidades necessárias a uma mulher, tais como dançar, desenhar, fazer tapeçarias e tocar piano. ${ }^{5}$

A educação feminina, considerada uma grande aliada no projeto de vida das famílias patriarcais, seria considerada tanto melhor quanto mais voltada para o desenvolvimento de competências voltadas para o exercício de atividades domésticas, sobretudo aquelas relacionadas ao entretenimento familiar. Nesse sentido, é importante destacar que a escritora inglesa Mary Wollstonecraft (1759-1797), no século XVIII, já denunciava a assimetria de propósitos educacionais entre homens e mulheres como causa de degradação da condição social feminina, afirmando que os homens "são preparados para profissões, e o casamento

${ }^{4}$ Cf. MIGUEL; BIROLI, Feminismo e política: uma introdução.

${ }^{5}$ Cf. FLAUBERT, Madame Bovary: costumes de provincia. 
não é considerado como a grande característica de suas vidas, enquanto as mulheres, ao contrário, não têm outro plano para estimular suas faculdades". ${ }^{6}$

Com isso, a primeira geração do feminismo - também conhecido como feminismo liberal, marcada pelas inestimáveis contribuições de Mary Wollstonecraft, Harriet Taylor Mill e Stuart Mill, na Europa, e Sojouner Truth, nos Estados Unidos - foi marcada pela denúncia da ausência de representação política das mulheres, escravos e operários. ${ }^{7}$

Ainda nesse sentido, destaca-se também o pensamento da escritora inglesa Virgínia Woolf (1882-1941), que ao se opor à disparidade de concessão de espaços de fala entre homens e mulheres, afirma ser a diferença entre homens e mulheres derivada, apenas e tão somente, de critérios convencionais que, por intermédio de um modelo educacional voltado para a subalternização feminina, desestimulam o interesse das mulheres, tornando juridicamente inviável sua participação na esfera pública. Em escritos em que se opõe ao patriarcado, na medida em que impede a conquista de independência financeira das mulheres, afirma a autora:

A principal distinção entre nós que estamos fora da sociedade e vocês que estão dentro da sociedade, é que, enquanto vocês farão uso dos meios proporcionados por sua posição - ligas, conferências, palestras, campanhas públicas desse tipo que a sua riqueza e influência política colocam ao seu alcance - nós ficando de fora, daremos experimentos não publicamente, com meios públicos, mas privadamente, com meios privados. ${ }^{8}$

A denúncia de que o modelo educacional associado às decisões políticas, que por sua vez consolidavam o padrão desejado, impedindo do ponto de vista jurídico com que mulheres pudessem se emancipar de seus senhores - avós, pais, maridos, ou mesmo, em casos excepcionais, de seus próprios filhos - desvelou as engrenagens de um modelo social pautado na dominação masculina, tornando questionáveis as noções de que mulheres seriam "naturalmente" inclinadas para a vida privada, bem como que elas estariam suficientemente tuteladas por intermédio da ação política de seus senhores.

Considerando que, em quase todos os países do mundo, até meados do século XX, o direito de votar era uma exclusividade masculina, não é difícil concordar com o argumento de que mecanismos evidentes de reprodução de subordinação operavam na sociedade moderna.

No Brasil, o processo eleitoral passou a assegurar o voto das mulheres apenas no ano de $1932^{\circ}$, durante o governo de Getúlio Vargas. Conquista esta que já representava avanço em relação aos períodos anteriores, mas que também padecia de suas incongruências, tendo em vista que apenas mulheres casadas, desde que expressamente autorizadas por seus maridos, viúvas e solteiras com renda própria encontravam-se contempladas pelo conceito legal de sufrágio "universal”.

\footnotetext{
${ }^{6}$ WOLLSTONECRAFT, Reivindicação dos direitos das mulheres, p. 93.

${ }^{7}$ Cf. MIGUEL; BIROLI, Feminismo e política: uma introdução.

${ }^{8}$ WOOLF, As mulheres devem chorar... Ou se unir contra a guerra: patriarcado e militarismo, p. 99.

${ }^{9} \mathrm{O}$ artigo 56 do Código Eleitoral brasileiro de 1932 garantiu o sistema de eleição pautado no sufrágio universal direto, voto secreto e representação proporcional. Cf. BRASIL, Decreto n. 21.076, de 24 de fevereiro de 1932. Código Eleitoral. Rio de Janeiro, 24 de fevereiro de 1932.
} 
Até que todas as restrições ao pleno exercício do direito ao voto feminino fossem banidas do ordenamento jurídico nacional se passaram dois anos. Vale dizer, somente no ano de 1934 o voto feminino, até então exercido em caráter facultativo, passou a ser previsto em caráter obrigatório.

Não há dúvidas de que a possibilidade de exercício do direito ao voto seja um marco jurídico de grande relevo para o processo de emancipação feminina. Sob a perspectiva normativa, é certo que o sufrágio universal tenha sido um importante passo na ocupação do espaço público por mulheres, em especial porque o processo de conquista desse direito evidenciou a incoerência dos fundamentos que pretendiam ver justificada a desqualificação pessoal das mulheres ${ }^{10}$ para a defesa de seus interesses em âmbito político.

Todavia, a mesma estrutura social que destinou a esfera privada como uma espécie de locus natural das mulheres, acabou se tornando responsável pelo costume de atribuir a esse grupo uma série de obrigações, geralmente relacionadas ao dever de cuidado para com o outro, que acabam por dificultar a efetiva participação das mulheres no espaço público.

Vale dizer, mecanismos menos evidentes de reprodução da subjugação feminina continuaram operando na sociedade: a subalternização velada, como imposição do dever de cuidado da família, dificuldade de exercício de direitos reprodutivos e relacionados à sexualidade, além da desvalorização social abstrata conferida ao sexo feminino, consistem apenas em alguns exemplos.

Diante de tal cenário, muitas mulheres, em busca de sua emancipação, não encontraram outra solução para o problema acima descrito senão a delegação das tarefas domésticas a outras pessoas, ou melhor, por via de regra, a outras mulheres. ${ }^{11}$ Através da realocação de outras mulheres para o exercício dessas atividades, ainda que de maneira pouco nítida aos olhares mais desatentos, criou-se uma incongruência dentro da própria agenda feminista, visto que nem todas as mulheres passaram a ser representadas pelo conceito de "todas as mulheres".

A título de exemplo podemos citar as observações da escritora norte-americana Angela Davis que, ao se referir ao processo de conquista de direitos das mulheres norteamericanas, afirma: "as líderes do movimento pelos direitos das mulheres não suspeitavam que a escravidão da população negra do Sul, a exploração econômica da mão de obra do Norte e a opressão social das mulheres estivesse relacionada de forma sistemática". ${ }^{12}$ Ora, isso significa que apesar das mulheres terem apoiado a campanha abolicionista nos Estados Unidos, não necessariamente conseguiam promover a integração entre sua consciência contrária à escravidão relacionando-a com a situação de cárcere em que muitas delas viviam.

Mesmo no interior do movimento feminista, dessarte, o abolicionismo da escravidão negra não era visto como algo relacionado ao regime de subjugação feminina. Mulheres brancas não conseguiam identificar-se com as mulheres negras, da mesma forma que mulheres pertencentes às classes mais abastadas não se identificavam com quaisquer outras mulheres, independentemente de sua cor de pele.

A busca por isonomia entre os sexos é árdua e perpassada por questões diversas, transversais e interseccionais, entre as quais, sem dúvida, a pobreza e a estigmatização social dela decorrente. Da observação de que o processo de libertação de algumas mulheres da

${ }^{10}$ Cf. MILL, Consideracões sobre o governo representativo.

${ }^{11}$ Cf. MIGUEL; BIROLI, Feminismo e política: uma introdução.

${ }^{12}$ DAVIS, Mulheres, rasa e classe, p. 75. 
esfera privada só tenha se tornado viável a partir do encarceramento de outras tantas meninas e mulheres em condição social menos favorecida - nesse mesmo espaço, ascende uma segunda geração do pensamento feminista, o qual, tendo por ponto de partida um legado teórico ambíguo, passa a questionar o próprio conceito de igualdade social e a função cogente das normas jurídicas.

\section{Considerações sobre a função enunciativa do Direito}

Diante da constatação de que o fim de um modo de opressão estava associado ao início de outro, a epistemologia feminista do século XX passou a questionar esquemas abstratos de defesa de direitos humanos. Pela valorização das vivências sociais diferenciadas, bem como pela constatação de que a sensibilidade diante da opressão é maior em relação aos indivíduos que dele são vítimas, do que propriamente em relação àqueles que afligem os outros com comportamentos violentos, buscou-se demonstrar a imbricação entre o público e o privado - ou seja, entre questões de natureza pessoal, social e política. ${ }^{13}$

Assim, se pela expressão "discriminação contra a mulher", de acordo com o artigo $1^{\circ}$ da Convenção para Eliminação de Todas as Formas de Discriminação Contra a Mulher (1979), deve ser compreendida toda distinção, exclusão ou restrição baseada no sexo que tenha por objeto ou resultado prejudicar ou anular o reconhecimento, gozo ou exercício pela mulher independentemente de seu estado civil, com base na igualdade do homem e da mulher - dos direitos humanos e liberdades fundamentais nos campos político, econômico, social, cultural e civil ou em qualquer outro campo ${ }^{14}$, é necessário investigar de qual “mulher” está-se a tratar.

Tendo em vista que grande parte dos países signatários desta Convenção, incluindo o Brasil, tenha ratificado tal documento dando-lhe validade em âmbito interno, é possível afirmar que a legislação contemporânea não mais se coadune com quaisquer manifestações de discriminação entre os sexos. Todavia, o estado da arte dos feminismos ${ }^{15}$ aponta a confluência de diferentes entraves que dificultam o pleno acesso das mulheres às instituições: a já mencionada diferença de socialização culturalmente imposta aos homens e às mulheres, questões relacionadas à classe social, ou ainda, raça e etnia são, por exemplo, situações em que dificuldades adicionais se sobrepõem umas às outras, tornando ainda mais dificultoso $o$ processo de inclusão de determinados grupos em relação a outros.

Dados apresentados pelo Sistema de Informação de Agravos de Notificação (SINAN), no ano de 2017, apontam que a taxa de homicídios para cada 100 mil habitantes foi de 64 para mulheres negras, e 63 para mulheres não negras (ou seja, brancas, amarelas e indígenas somadas).

Nesse sentido, afirmam que, muito embora não seja possível determinar se homicídios de mulheres são efetivamente motivados por fatores de gênero (feminicídios), é certo que $30 \%$ destas foram mortas em casa, enquanto entre homens este índice cai para

\footnotetext{
${ }^{13}$ Cf. MIGUEL; BIROLI, Feminismo e politica: uma introdução.

14 BRASIL. Decreto n 65.810, de 8 de dezembro de 1969. Promulga a Convenção Internacional sobre a eliminação de todas as formas de discriminação racial. Diário Oficial [da] República Federativa do Brasil. Brasília, 8 de dezembro de 1969.

15 Propositalmente citados no plural, haja vista a dimensão de que o termo seja antes associado ao que se convencionou denominar de "conceito guarda-chuva", pois, apesar de ser relacionado a um mesmo grupo focal, é capaz de contemplar a pluralidade de pautas relacionadas à questão de gênero.
} 
11\%. Estes morreram mais em via pública (46\%), local em que $29 \%$ das mulheres foram assassinadas.

Vale destacar também que no mesmo ano foram registrados 12.112 casos de violência contra pessoas trans, e 257.764 casos de violência contra homossexuais ou bissexuais no Brasil. Foram 11 agressões contra pessoas trans e 214 contra pessoas homo/bi no país, a cada dia. ${ }^{16}$ As diferentes formas de opressão que se destinam a mulheres acabam sendo somadas, agravando suas situações social e jurídica. Mecanismo institucionais corroboram para a promoção do distanciamento entre a realidade e o dever-ser. Portanto, essa exposição, que ao partir da adoção do enfoque da questão de gênero não pretende ser neutra, parte do pressuposto de que o sexismo não pode ser analisado de maneira isolada, na medida em que resulta de processos culturais complexos, em que questões interseccionais e transversais perpassam o debate. Nesses casos, é forçoso reconhecer que o direito passa a exercer, para determinadas cliques, função meramente enunciativa.

Considerando a teoria tridimensional do direito, desenvolvida pelo jurista brasileiro Miguel Reale, a qual aponta a interação entre fato social, valoração objetiva e normatividade ${ }^{17}$ como sendo elementos essenciais para a construção do ordenamento jurídico; considerando que a discriminação e a violência contra mulheres seja um fato social inegável; considerando, por fim, que existam normas jurídicas, - a exemplo dos tratados internacionais ratificados e internalizados em nosso país, assim como normas produzidas pelo Poder Legislativo no sentido de conferir especial proteção às mulheres - torna-se imprescindível a investigação sobre os motivos pelos quais, em nossa sociedade, algumas mulheres se encontram mais vulneráveis que outras.

O reconhecimento da identidade feminina, portanto, ainda hoje consiste em problema a ser superado, pois apenas um perfil de mulher tende a ser universalizado, razão pela qual não se considera absurda a afirmação de que a "mulher" juridicamente tutelada possui determinada cor de pele, endereço e renda determinada - o que corrobora para que a multiplicidade das dimensões da luta por reconhecimento e, sobretudo, pela efetivação de direitos de parcela significativa de pessoas, seja relegado às sombras do esquecimento, tornando-se opaco mesmo no contexto dos discursos feministas.

Para que a categoria "mulher" não seja articulada na epistemologia feminista como uma espécie de "Cavalo de Tróia", no qual imagem e conteúdo, apesar de distintos, acabam se sobrepondo um ao outro, faz-se necessário ter cautela. ${ }^{18}$ Não se pode mais ignorar que as estatísticas que apontam vertiginosa diferença entre classes sociais, gênero e cor da pele sejam apontadas como mera obra do acaso ou coincidência. Os múltiplos mecanismos do etnocentrismo, responsáveis por oprimir e segregar indivíduos, por sua vez, operam, cada vez mais, sob aparência da mais absoluta neutralidade, tal como se não pudessem ser modicados por ter sido "sempre assim". Considerando que a impermeabilidade em relação às diferentes vivências das mulheres dos extratos sociais historicamente desprestigiados em nossa sociedade possam ser estatisticamente observadas, a seguir serão apresentados alguns dados sobre o tema.

\footnotetext{
${ }^{16}$ Cf. Mapa da violência de Gênero: mulheres são quase 67\% das vítimas de agressão física no Brasil. 11 jul. 2019.

${ }^{17}$ Cf. REALE, Lições preliminares de direito, pp. 60-4.

${ }^{18}$ Cf. MIGUEL; BIROLI, Feminismo e politica: uma introdução.
} 


\section{Interseccionalidade e transversalidade das questões de gênero nas políticas públicas}

Tendo em vista o exame de que desvantagens sociais possam agir em associação, para além da denúncia da naturalização da opressão às mulheres, torna-se imprescindível o reconhecimento e a superação das desigualdades sociais que, de forma sorrateira, retroalimentam o fenômeno da marginalização das mulheres. Nesse sentido, não restam dúvidas de que as problematizações feministas se confundam tanto com o problema da dominação masculina em si mesma, como também em relação ao exercício do poder político e, portanto, com a própria noção de governo democrático.

A precariedade de políticas públicas especificamente voltadas para questões de gênero em nosso país não se coaduna com o múltiplo cenário de experiências e vivências femininas, as quais distanciam-se em muitos níveis diferentes do estereótipo feminino. ${ }^{19}$

Levando-se em consideração que políticas públicas sejam uma forma de interação entre a sociedade civil e o Estado, capazes de transformar os princípios constitucionais norteadores de nossa organização político-social em ação $\mathrm{O}^{20}$; e também que, no Brasil, apenas 9\% dos cargos do Poder Legislativo são ocupados por mulheres, podemos ter uma dimensão da gravidade de cenário político contemporâneo.

Além disso, dada a pluralidade de pautas feministas e de reivindicação dos direitos das mulheres, não há garantias de que as representantes políticas do sexo feminino, apenas por serem mulheres, compartilhem da mesma agenda pública e ideais, de modo a se tornarem legítimas porta-vozes da complexidade dos interesses envolvidos.

A ausência de clareza das autoridades políticas acerca das diferenças entre políticas públicas "para mulheres" - as quais geralmente possuem cunho assistencialista, voltando-se para questões relacionadas à reprodução e família - e políticas públicas "de gênero" mais abrangentes, na medida em que se prestam a corrigir assimetrias sociais encobertadas por usos e costumes, certamente são agravadas pela questão da baixa representatividade feminina na seara legislativa. ${ }^{21}$

A política da presença e, consequentemente, os debates de gênero, surgem como uma forma de dar maior visibilidade aos grupos focais que sofrem ou que se encontram em condições de maior vulnerabilidade à violência. A despeito de todo o sistema internacional de direitos humanos, assim como da legislação interna, que declaram a proteção contra toda forma de discriminação contra os indivíduos, incluindo a mulher, é certo que a busca pela concretização do ideal de igualdade de gênero permanece como um privilégio, e como tal, apresenta-se como algo inacessível para muitas pessoas.

A negação da transcendência feminina, nesse sentido, constitui-se fator decisivo para a compreensão do processo de formação da própria identidade feminina, reforçando-se estereótipos que reconhecem as mulheres não como sujeitos de direitos, mas, sim, como objetos a serem tutelados e protegidos pela legislação - sem que se questionem as causas subjacentes a tamanha exposição à violência que este grupo sofre.

\footnotetext{
${ }^{19}$ Cf. MIGUEL; BIROLI, Feminismo e política: uma introdução.

${ }^{20}$ Cf. BANDEIRA; ALMEIDA, "A transversalidade de gênero nas políticas públicas".

${ }^{21}$ Cf. BANDEIRA; ALMEIDA, "A transversalidade de gênero nas políticas públicas".
} 
Considerando, por fim, que o pertencimento dos indivíduos, desde o período pósrevolucionário francês, tenha sido apontado como hipoteticamente universal, passa a ser dever das ciências humanas, e em especial da filosofia política, questionar a ferramenta conceitual utilizada, considerando que os ideais de justiça e igualdade modernos tenham sido esboçados por indivíduos do sexo masculino, brancos, pertencentes às altas classes sociais e, como regra, de orientação sexual heteronormativa. ${ }^{22}$ É imperativo a um sistema de governo que pretenda ser reconhecido como democrático que questões de gênero, compreendidas em todas as suas possíveis intersecções (morais, teóricas e técnicas), perpassem de forma transversal o debate político contemporâneo, permitindo que as dimensões ideológicas prejudiciais à noção de isonomia material sejam colocadas em xeque.

\section{Considerações finais}

A desvantagem sistêmica de mulheres em relação aos homens é facilmente demonstrada por intermédio de dados estatísticos; a questão da violência, pode-se dizer, é apenas uma entre as várias formas de subjugação feminina.

O problema torna-se ainda mais grave, contudo, ao se observar que esse mesmo processo de discriminação e violência também opera internamente ao próprio grupo focal das mulheres, de modo que processos de discriminação velados acabam por privilegiar mulheres brancas em relação às negras, mulheres saudáveis em relação àquelas que apresentem limitações físicas, funcionais ou intelectuais, mulheres cis em relação às transgênero etc.

Não há como ignorar o fato de que a discriminação de gênero, quando entrelaçada com fatores como pobreza e desigualdade social, tem seus efeitos potencializados, tornandose ainda mais nociva.

Ao longo deste ensaio pretendeu-se demonstrar, ainda que de forma resumida, o perigo da crença tipicamente moderna na função enunciativa do Direito.

Vale dizer, a mera declaração da igualdade não tem o condão de transformar a sociedade como um todo, e tampouco os seus indivíduos isoladamente considerados. Reformas substanciais devem acompanhar tais medidas, sob pena de ineficácia.

A defesa da transversalidade de gênero nas políticas públicas, nesse sentido, deve ter por escopo o fortalecimento da cidadania, de modo que possamos observar a mulher para além da dimensão identitária que a separa dos homens, e, consequentemente, o abandono da associação do símbolo feminino às noções de fragilidade e incapacidade. Em especial, deve contribuir para o desvelamento dos problemas sociais que decorrem da intersecção entre gênero e miséria, impedindo, assim, que subgrupos venham a ser apenas nominalmente representados. Vale dizer, estratégias políticas neutras para gênero não produzem impactos iguais a todas as mulheres, consequentemente, negam a um número significativo de indivíduos o acesso a condições de existência minimamente dignos.

A adoção de políticas públicas, nesse sentido, pode beneficiar a sociedade ao descortinar o processo de naturalização da violência contra as mulheres. Contudo, não se pode perder de vista o fato de que ações afirmativas como instrumento para superação da

${ }^{22}$ Cf. BANDEIRA; ALMEIDA, "A transversalidade de gênero nas políticas públicas". 
desigualdade não são, propriamente, o que se denomina de uma "novidade", razão pela qual a superação da naturalização da violência contra as mulheres, por intermédio deste instrumento político-normativo, só será possível se levar-se em consideração que as destinatárias das normas não estão sendo igualmente beneficiadas pelas medidas nominalmente adotadas.

Caberá à filosofia política contemporânea a promoção de debates que venham a auxiliar na identificação dos pontos de maior vulnerabilidade social das mulheres, de modo a facilitar a compreensão do fenômeno em questão, bem como a definição de teorias que, estrategicamente definidas, permitam com que o exercício do poder político seja beneficiado pela diversidade humana, tornando-se mais democrático.

\section{Referências bibliográficas}

BANDEIRA, L. M.; ALMEIDA, T. M. C. de. "A transversalidade de gênero nas políticas públicas”, In: Revista do CEAM, v. 2, n. 1, pp. 35-46, 2013.

BRASIL. Constituição (1988). Disponível em: http://www.planalto.gov.br/ccivil_03/constituicao/constituicao.htm. Acesso em: 26 mar.2017.

BRASIL. Decreto 1.9841, de 22 de outubro de 1945. Promulga a carta das Nações Unidas, da qual faz parte integrante o anexo Estatuto da Corte Internacional de Justiça, assinada em São Francisco, a 26 de junho de 1945, por ocasião da Conferência de Organização Internacional das Nações Unidas. Diário Oficial [da] República Federativa do Brasil. Brasília, DF, 22 outubro 1945. Disponível em: http://www.planalto.gov.br/ccivil_03/decreto/19301949/d19841.htm. Acesso em: 9 jun.2017.

BRASIL. Decreto n 65.810, de 8 de dezembro de 1969. Promulga a Convenção Internacional sobre a eliminação de todas as formas de discriminação racial. Diário Oficial [da] República Federativa do Brasil. Brasília, 8 de dezembro de 1969. Disponível em: http://legis.senado.gov.br/legislacao/ListaTextoIntegral.action?id=9483. Acesso em: 2 jun.2017.

BRASIL. Gênero e pobreza no Brasil: relatório final do projeto Governabilidad Democratica de Género en America Latina y el Caribe. CEPAL, SPM: Brasília, 2005.

BRASIL. Violência LGBTFóbicas no Brasil: dados da violência/ elaboração de Marcos Vinícius Moura Silva - Documento eletrônico - Brasília: Ministério dos Direitos Humanos, 2018. Disponível em: https://www.mdh.gov.br/biblioteca/consultorias/lgbt/violencialgbtfobicas-no-brasil-dados-da-violencia. Acesso: 07 fev.2020.

DAVIS, A. Mulheres, raça e classe. Tradução Heci Regina Candiani. São Paulo: Boitempo.

FLAUBERT, G. Madame Bovary: costumes de provincia. Tradução Fúlvia M. L. Moretto. São Paulo: Nova Alexandria, 2007. 
Mapa da violência de Gênero: mulheres são quase 67\% das vítimas de agressão física no Brasil. Documento eletrônico. 11 jul.2019. Disponível em: http://www.generonumero.media/mapa-da-violencia-de-genero-mulheres-67-agressaofisica/. Acesso: 12 fev.2020.

MIGUEL, L. F.; BIROLI, F. Feminismo e politica: uma introducão. São Paulo: Boitempo, 2014. MILL, J. S. A sujeição das mulheres. Tradução Paulo Geiger. São Paulo: Companhia das Letras, 2017.

. Considerações sobre o governo representativo. Tradução Denise Bottman. Porto Alegre, RS: L\&PM, 2018.

REALE, Miguel. Lições preliminares de Direito. São Paulo: Saraiva, 2002. Filosofia do Direito. São Paulo: Saraiva, 2002.

ROCHA, Carmem Lúcia Antunes. "Ação afirmativa: o conteúdo democrático do princípio da igualdade jurídica". In: Revista de Informação Legislativa. V. 33, n. 131, pp. 283-295, 1996. Disponível em: http://www2.senado.leg.br/bdsf/handle/id/176462. Acesso em: 2 jun.2017.

\begin{tabular}{cccccc}
\multicolumn{4}{c}{. “O princípio da dignidade da pessoa humana e a exclusão social”. In: Revista Interesse } \\
\hline Público, & n. $4, \quad$ pp. & 23-49, & 1999. & Disponível
\end{tabular} http://egov.ufsc.br/portal/sites/default/files/anexos/32229-38415-1-PB.pdf. Acesso em: 1 jun.2017.

"Ação Afirmativa: O conteúdo democrático do princípio da igualdade jurídica". In: Revista de informação legislativa. v. 33., n. 131, pp. 283-295, 1996. Disponível em: http://www2.senado.leg.br/bdsf/item/id/176462. Acesso em 30 jun. 2016.

WAISELFISZ, J. J. Mapa da violência 2015: Homicídio de mulheres no Brasil. Documento eletrônico. Brasília: Ministério das Mulheres, da Igualdade Racial e dos Direitos Humanos, 2015. Disponível em:

https://www.mapadaviolencia.org.br/pdf2015/MapaViolencia_2015_mulheres.pdf. Acesso: 07 fev.2020.

WOOLF, V. As mulheres devem chorar... Ou se unir contra a guerra: patriarcado e militarismo. Tradução Tomaz Tadeu. Belo Horizonte: Autêntica, 2019. 